\title{
Ganglioglial differentiation in a medulloblastoma with extensive nodularity
}

\section{Diferenciação ganglioglial em um meduloblastoma com extensa nodularidade}

Bruna Ferreira Bernert1' Alex Roman²; Paulo Carboni Jr. (in memoriam) ${ }^{3}$; Luiz Fernando Bleggi Torres ${ }^{4}$

\begin{abstract}
We report the case of a 2 month-old patient with a large, probably congenital, posterior fossa tumor. Hematoxylin and eosin staining (HE), reticulin and immunohistochemistry revealed a medulloblastoma with extensive nodularity, showing ganglioglial differentiation, high proliferative index in the primitive neuroectodermal tumor (PNET) area and low proliferative index in the ganglioglial maturation area. Ganglioglial differentiation is a rare event in medulloblastomas and its mechanism is still unknown. Previous surgery, radiation and chemotherapy may contribute to differentiation in astrocytic and nerve cells. In this case, however, the differentiation was already present in the first specimen, prior to any surgical or therapeutic procedure.
\end{abstract}

Key words: medulloblastoma; cell differentiation; immunohistochemistry; congenital brain neoplasms.

\section{INTRODUCTION}

Medulloblastomas are among the most frequent primary central nervous system (CNS) tumors in children, accounting for approximately $20 \%$ of cases in the first two decades of life. However, they are rare in adults. The origin of medulloblastomas seems to be linked with the external granular layer of the cerebellum due to the activation of Hedgehog and Wnt pathways. This would contribute to the development of the classic and nodular variants, whereas further genetic abnormalities in $c-m y c, N-m y c, 17 \mathrm{p}$, human telomerase reverse transcriptase (hTERT) and plateletderived growth factor receptors (PDGFR), amongst others, would contribute to the development of the large/anaplastic variant ${ }^{(3,4,16)}$.

Some medulloblastomas might present cell differentiation and maturation. The occurrence of this differentiation is rarely described in medulloblastomas, and neither the exact mechanism of maturation in neuronal and glial cells nor its prognosis are well established yet ${ }^{(11)}$.
This report refers to a two-month-old boy with a large posterior fossa tumor exhibiting an unusual cell differentiation and maturation.

\section{CASE REPORT}

A two-month-old boy presented with irritability, hypoactivity, nausea and vomiting for two weeks. There was an increase in the cephalic perimeter, ingurgitated veins and fontanel size. He was admitted with progression of sleepiness, evolving to extreme lethargy and weak response to pain stimulation. Laboratory investigation failed to demonstrate any relevant alterations. Computerized tomography (CT Scan) and magnetic resonance imaging (MRI) showed a heterogeneous lesion in the posterior fossa, with obliteration of the fourth ventricle and dilation of the third and lateral ventricles (Figure 1). The patient underwent external ventricular drainage with improvement in clinical signs followed by microsurgery for resection of the posterior fossa tumor.

First submission on 26/04/13; last submission on 05/08/13; accepted for publication on 06/08/13; published on 20/12/13

1. Graduate student in Medicine at Universidade Federal do Paraná (UFPR); Scientific Research Grant at UFPR.

2. Resident in Neurosurgery at the Neurosurgery Department of Hospital Infantil Pequeno Príncipe.

3. Neurosurgeon at the Neurosurgery Department of Hospital Infantil Pequeno Príncipe.

4. PhD in Neuropathology at University of London; professor at the Medical Pathology Department-UFPR; researcher at Instituto de Pesquisa Pelé Pequeno Príncipe 


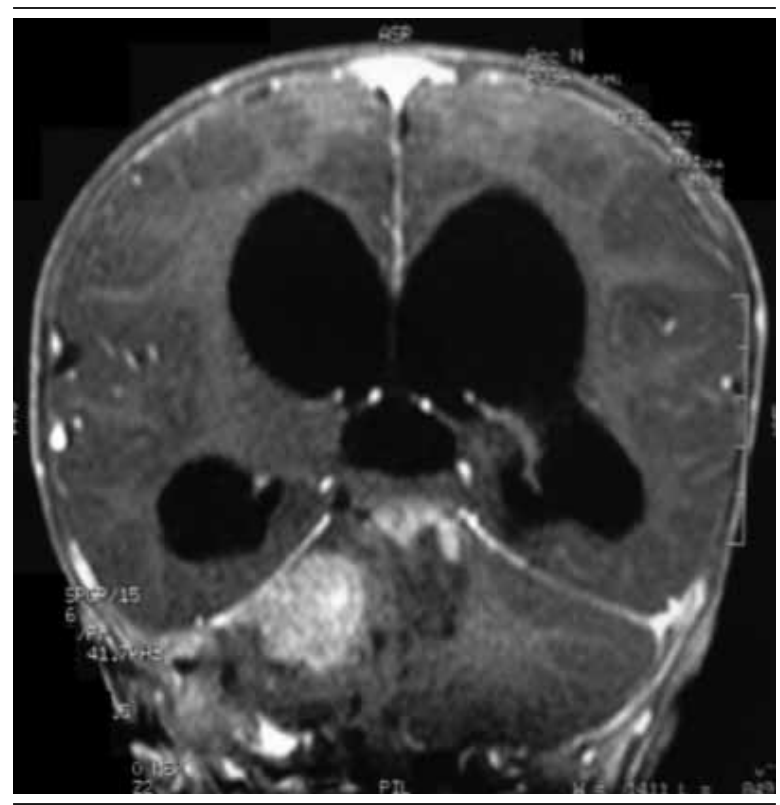

FIGURE 1 - MRI (T1 post-contrast) of posterior fossa showing a beterogeneous tumor in the cerebellum

MRI: magnetic resonance imaging.

Several fragments of gray and elastic tissue measuring $6.5 \times$ $6.0 \times 3.0 \mathrm{~cm}$ and weighing 50 grams were sent to histopathological examination. Histological sections showed a heterogeneous lesion with areas of nodular arrangement in continuity with diffuse and highly fibrillary areas (Figure 2). In the internodular areas, tumor cells were small with scanty cytoplasm and relatively uniform nuclei, exhibiting mitoses and apoptotic bodies. In the nodular, diffuse and fibrillary areas (Figures $\mathbf{3}$ and $\mathbf{4}$ ), there was reduced nuclear density and the tumor cells showed maturation towards larger cells, including mature-like nerve cells. Reticulin preparation highlighted the nodular arrangement of the tumor, showing large reticulin-free zones surrounded by dense intercellular reticulin fiber areas. Immunohistochemistry showed weak positivity for synaptophysin (Figure 5) in the nodular areas, whereas the diffuse areas were strongly positive. Glial fibrillary acidic protein (GFAP) (Figure 6) was also positive amongst the larger cells and negative in the nodular areas. Proliferative index (anti-Ki67 - Dako) was $80 \%$ in small cells and 3\%-5\% in the large cell area. Thus, a medulloblastoma with extensive nodularity and ganglioglial differentiation was diagnosed.

Subsequent MRI showed a residual tumor in the posterior fossa, and the patient underwent a second procedure for microsurgical tumor resection, with no further complications. The patient was discharged from hospital and started on chemotherapy with methotrexate and vincristine. Four months later he was once more admitted with lethargy. CT Scan demonstrated bilateral extra- axial fluid collections and subdural drainage was performed. A subsequent MRI demonstrated a nodular lesion in the posterior fossa of approximately $7.4 \mathrm{~mm}$ in diameter and peri-medullary enhancement, especially in the cauda equina region.

\section{DISCUSSION}

The World Health Organization (WHO) classification lists four types of medulloblastoma: desmoplastic/nodular, medulloblastoma with extensive nodularity (MBEN), anaplastic and large-cell. Different types of medulloblastomas are associated with different prognosis. For instance, large-cell medulloblastomas have particularly poor prognosis, while MBEN and desmoplastic/ nodular are associated with better prognosis ${ }^{(13)}$.

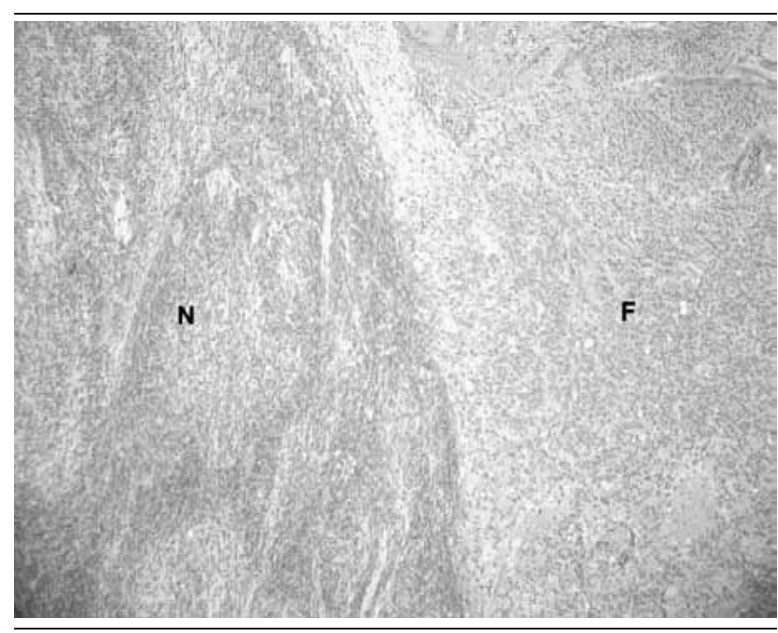

FIGURE 2 -MBEN showing nodular area ( $N$ ) in continuity with more fibrillary and differentiated region (F) (HE, 20 $\times)$

MBEN: medulloblastoma with extensive nodularity; HE: hematoxylin and eosin.

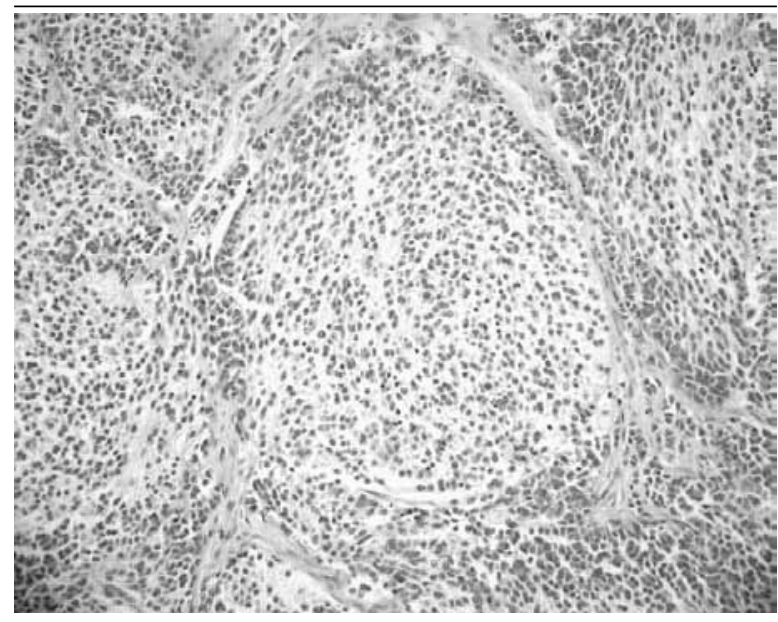

FIGURE 3 -Nodular area with reduced nuclear density composed of small cells (HE, 200x)

HE: hematoxylin and eosin. 


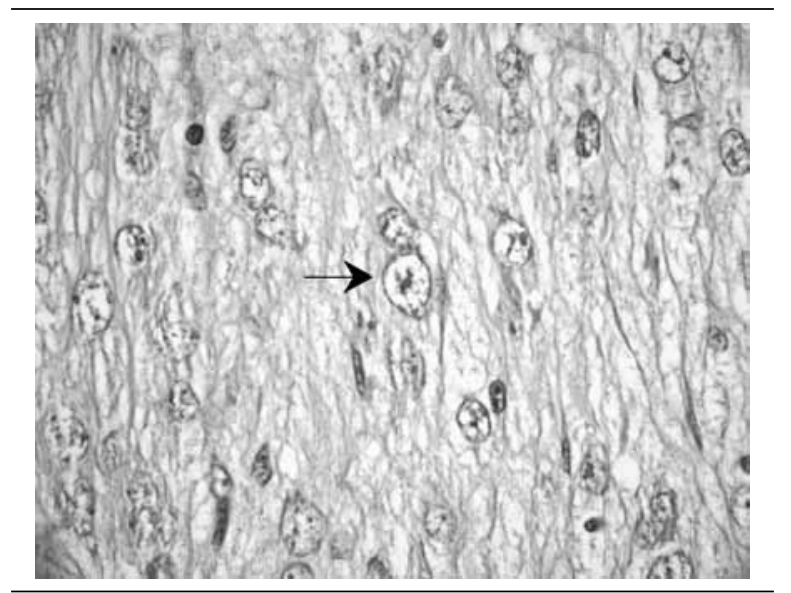

FIGURE 4 - Area of ganglioglial differentiation showing mature-like ganglion cells (arrow) and astrocytes in a fibrillary background (HE, 400×)

HE: hematoxylin and eosin.

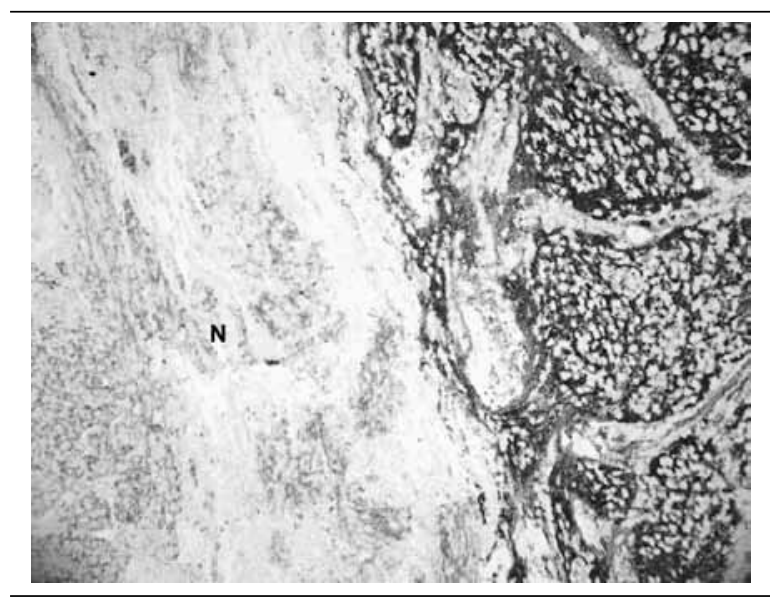

FIGURE 5 - Synaptophysin immunobistochemistry is very strong in the ganglioglial fibrillary areas and weak in the nodular $(N)$ area (Synaptophysin) $D A B, 100 \times)$

DAB: diaminobenzidine.

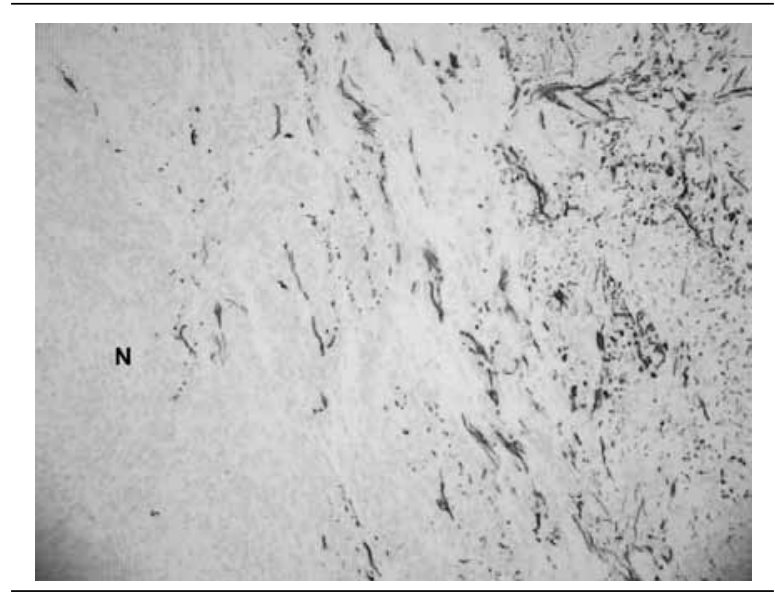

FIGURE $\mathbf{6}$-GFAP immunohistochemistry is strong in the ganglioglial area and negative in the nodular (N) areas (GFAP/DAB, 100 $\times$ )

GFAP: glial fibrillary acidic protein; DAB: diaminobenzidine.
The desmoplastic/nodular variant constitutes $5 \%-25 \%$ of pediatric medulloblastomas. It has a heterogeneous structure consisting of regions with dense intercellular reticulin and nodular reticulin-free zones ("pale islands"), in which tumor cells may show a neuronal phenotype. This variant is distinctive in two ways: it is particularly prevalent in infancy (representing $57 \%$ of medulloblastomas in infants aged $<3$ years, including MBEN), and has a better outcome in comparison with classic medulloblastomas across the pediatric range ${ }^{(14)}$.

MBEN, which corresponds to the present case variant, is rare and occurs mainly in infants, accounting for less than $3 \%$ of medulloblastomas. The tumor reveals signs of neuronal and astrocytic differentiation and, following radiotherapy and/or chemotherapy, this extensive nodular variant may occasionally undergo further maturation to tumors predominantly composed of ganglion cells ${ }^{(8,13,14)}$. The desmoplastic variants of medulloblastoma, mainly MBEN, have been more commonly observed in comparison with other medulloblastoma types associated with nevoid basal cell carcinoma syndrome (NBCCS). Garrè et al. ${ }^{(5)}$ diagnosed NBCCS in $22.7 \%$ of patients with desmoplastic variants and $41 \%$ of patients in the group of medulloblastoma with extensive nodularity (MBEN). NBCCS, also known as Gorlin syndrome, is a hereditary condition characterized by a wide range of developmental abnormalities and a predisposition to develop early-onset neoplasms, including medulloblastomas, which are included among the minor criteria for clinical diagnosis of the syndrome. It is caused by mutations in the PTCH1 gene and is transmitted in an autosomal dominant manner with high penetrance and variable expressivity. Radiation therapy for medulloblastoma may induce invasive basal cell carcinomas in the radiation field. Therefore, early diagnosis of this syndrome is vital, aiming at a selection of appropriate adjuvant treatment (avoiding radiotherapy in patients affected by NBCCS and/or MBEN), close clinical follow-up, investigations and family genetic counseling ${ }^{(1,5,12)}$. In this report we were unable to confirm any familial genetic disorders.

The clinical presentation of medulloblastomas includes obstruction of CSF and cerebellar dysfunction. Headache, vomiting and lethargy are generally present ${ }^{(16)}$. Congenital presentation has been already documented, although rare, once all congenital CNS tumors represent less than $5 \%$ of CNS tumors in childhood ${ }^{(6 .}$ 7). The patient described exhibited clinical signs and symptoms, CT Scan and MRI findings compatible with a posterior fossa lesion. Furthermore, the histological examination confirmed the diagnosis of medulloblastoma. On contrast-enhanced MRI, a marked grapelike appearance of multiple coalescing nodules strongly suggests MBEN, especially when detected in an infant 
or young child. This medulloblastoma variant may reveal other presentations. In the present report it appears like a solid, oval and heterogeneous image. However, this finding does not invalidate the histopathological diagnosis ${ }^{(10,15)}$.

Ganglioglial differentiation is a rareevent in medulloblastomas and its mechanism is still unknown. Previous surgery, radiation and chemotherapy could promote a cytostatic effect and contribute to a post-mitotic differentiation in astrocytic and nerve cells. This young boy medulloblastoma, however, revealed ganglioglial differentiation in the first specimen. The impact of such unusual differentiation in survival is still a matter of controversy in the

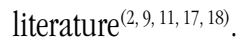

\section{RESUMO}

Paciente de dois meses de idade apresentando grande tumor, provavelmente congênito, de fossa posterior. As colorações de hematoxilina e eosina (HE), reticulina e imuno-bistoquímica revelaram meduloblastoma com extensa nodularidade, exibindo diferenciação ganglioglial, alto indice proliferativo na região de tumor neuroectodérmico primitivo e baixo índice proliferativo na área de maturação ganglioglial. Diferenciação ganglioglial é um evento raro em meduloblastomas e seu mecanismo ainda é desconhecido. Cirurgia prévia, radiação e quimioterapia podem contribuir para diferenciação em células astrocitárias e nervosas. Neste caso, entretanto, a diferenciação já estava presente no primeiro espécime, antes de cirurgias prévias ou procedimentos terapêuticos.

Unitermos: meduloblastoma; diferenciação celular; imuno-histoquímica; neoplasias encefálicas congênitas.

\section{REFERENCES}

1. AMLASHI, S. F. et al. Nevoid basal cell carcinoma syndrome: relation with desmoplastic medulloblastoma in infancy. A population-based study and review of the literature. Cancer, v. 98, n. 3, p. 618-24, 2003.

2. BURGER, P. C. et al. Differentiation in the medulloblastoma. A histological and immunohistochemical study. Acta Neuropathol, v. 73, n. 2, p. 115-23, 1987.

3. DICKSON, D. W. et al. Medulloblastoma with glial and rhabdomyoblastic differentiation. A myoglobin and glial fibrillary acidic protein immunohistochemical and ultrastructural study. J Neuropathol Exp Neurol, v. 42, n. 6, p. 639-47, 1983.

4. EBERHART, C. G.; BURGER, P. C. Anaplasia and grading in medulloblastomas. Brain Pathol, v. 13, n. 3, p. 376-85, 2003.

5. GARRÈ, M. L. et al. Medulloblastoma variants: age-dependent occurrence and relation to Gorlin syndrome--a new clinical perspective. Clin Cancer Res, v. 15, n. 7, p. 2463-71, 2009.

6. HALPERIN, E. C. Neonatal neoplasms. Int J Radiat Oncol Biol Phys, v. 47, n. 1, p. 171-8, 2000.

7. HWANG, S. W.; SU, J. M.; JEA, A. Diagnosis and management of brain and spinal cord tumors in the neonate. Semin Fetal Neonatal Med, v. 17, n. 4, p. 202-6, 2012.

8. JÓWIAK, J. et al. Favourable prognosis in medulloblastoma with extensive nodularity is associated with mitogen-activated protein kinase upregulation. Folia Neuropathol, v. 49, n. 4, p. 257-61, 2011.
9. KADOTA, Y.; ARAI, H.; SATO, K. Neural differentiation and maturation in metastatic medulloblastoma--case report. Neurol Med Chir (Tokyo), v. 35 , n. 1, p. 32-5, 1995.

10. KOELLER, K. K.; RUSHING, E. J. From the archives of the AFIP: medulloblastoma: a comprehensive review with radiologic-pathologic correlation. Radiographics, v. 23, n. 6, p. 1613-37, 2003.

11. KUDO, M. et al. Ganglioglial differentiation in medulloblastoma. Acto Pathol Jpn, v. 40, n. 1, p. 50-6, 1990.

12. LO MUZIO, L. Nevoid basal cell carcinoma syndrome (Gorlin syndrome). Orphanet J Rare Dis, v. 3, p. 32, 2008.

13. LOUIS, D. N. et al. The $2007 \mathrm{WHO}$ classification of tumours of the central nervous system. Acta Neuropathol, v. 114, n. 2, p. 97-109, 2007.

14. MCMANAMY, C. S. et al. Nodule formation and desmoplasia in medulloblastomas-defining the nodular/desmoplastic variant and its biological behavior. Brain Pathol, v. 17, n. 2, p. 151-64, 2007.

15. OSBORN, A. G. et al. The new World Health Organization classification of central nervous system tumors: what can the neuroradiologist really say? AJNR Am J Neuroradiol, v. 33, n. 5, p. 795-802, 2012.

16. PACKER, R. J. et al. Medulloblastoma: clinical and biologic aspects. Neuro Oncol, v. 1, n. 3, p. 232-50, 1999.

17. PACKER, R. J. et al. Prognostic importance of cellular differentiation in medulloblastoma of childhood. J Neurosurg, v. 61, n. 2, p. 296-301, 1984

18. SIME, P. J. et al. Differentiation in medulloblastomas and other primitive neuroectodermal tumours. Br J Neurosurg, v. 3, n. 1, p. 89$100,1989$.

\section{MAILING ADDRESS}

